\title{
Circulating tumour cell enumeration does not correlate with Miller-Payne grade in a cohort of breast cancer patients undergoing neoadjuvant chemotherapy
}

\section{Sharon 0'Toole ( $\sim$ shotoole@tcd.ie)}

University of Dublin Trinity College https://orcid.org/0000-0002-9260-3225

Cathy Spillane

University of Dublin Trinity College

Yanmei Huang

University of Dublin Trinity College, Xinxiang University Hospital, China

Marie Fitzgerald

University of Dublin Trinity College

Brendan Ffrench

University of Dublin Trinity College

Bashir Mohamed

University of Dublin Trinity College

Mark Ward

University of Dublin Trinity College

Michael Gallagher

University of Dublin Trinity College

\section{Tanya Kelly}

University of Dublin Trinity College

Cathal O'Brien

Saint James's Hospital Dublin

Carmel Ruttle

University of Dublin Trinity College

Anna Bogdanska

University of Dublin Trinity College

Cara Martin

University of Dublin Trinity College

Dorinda Mullen

University of Dublin Trinity College

Elizabeth Connolly

Saint James's Hospital Dublin 


\section{Sarah A McGarrigle}

University of Dublin Trinity College

John Kennedy

Saint James's Hospital Dublin

John J O'Leary

University of Dublin Trinity College

\section{Research article}

Keywords: Breast cancer; Circulating tumour cells (CTCs); neoadjuvant chemotherapy (NAC); pathological complete response (pCR); Miller-Payne grade.

Posted Date: September 7th, 2019

DOI: https://doi.org/10.21203/rs.2.14080/v1

License: (c) (i) This work is licensed under a Creative Commons Attribution 4.0 International License.

Read Full License

Version of Record: A version of this preprint was published at Breast Cancer Research and Treatment on May 6th, 2020. See the published version at https://doi.org/10.1007/s10549-020-05658-7. 


\section{Abstract}

Background: Detection and enumeration of Circulating Tumour Cells (CTCs) has been evaluated in many cancers such as breast cancer. However, the full prognostic and predictive power of CTCs for cancer cannot currently be harnessed, and the association between pathological complete response in patients receiving neoadjuvant chemotherapy for breast cancer and CTCs is still not clear. The aim of this study was to assess if CTCs could be used to predict pathological response to neoadjuvant chemotherapy in breast cancer patients. Methods: 26 patients were recruited, and blood samples taken pre- and postneoadjuvant chemotherapy. CTCs were isolated using the ScreenCell device and stained using a modified Giemsa stain. CTCs were enumerated by 2 pathologists and classified as single CTCs, doublets clusters/microemboli. Counts were then correlated to the pathological response as measured by the Miller-Payne grading system. The associations between CTCs and clusters and pathological variables were evaluated with $\chi 2$ or ANOVA tests performed in the SPSS 24.0 statistics software. Results: $89 \%$ of the patients had invasive ductal carcinoma and $11 \%$ invasive lobular carcinoma. At baseline $85 \%$ of patients had CTCs present and only 4 patients were CTC negative. Median baseline CTC count was 7 (0161) CTCs per $3 \mathrm{mls}$ of whole blood. Post chemotherapy, $58 \%$ of the patients had an increase in CTCs. This change in CTC count did not correlate with the Miller Payne grade of response to chemotherapy. No significant association was identified between the number of CTCs and clinical characteristics, including patient age, receptor status, tumour grade, disease type, lymph node metastasis, lymphovascular space invasion, radiological response or clinical or pathological stage. However, we did observe a correlation between pre-treatment CTC counts and body mass index, $p<0.05$. Conclusions: There was no correlation between the pre- and post-chemotherapy total number of CTCs/clusters and the Miller Payne grade. It is not enough to evaluate pathological response for neoadjuvant chemotherapy for breast cancer patients utilising CTCs identified by Giemsa staining alone. Additional characterisation is needed to further characterise CTCs isolated pre- and post-chemotherapy. Long-term follow-up of these patients will determine the significance of CTCs in breast cancer patients undergoing neoadjuvant chemotherapy.

\section{Background}

Breast cancer is a major public health issue globally, representing the most common cancer in women and one in ten of all newly diagnosed cancers. It is also the main cause of female cancer death globally, with 2,088,849 cases diagnosed in 2018 and 626,679 deaths [1]. Neoadjuvant chemotherapy (NAC) is now a standard treatment for breast cancer, often shrinking the tumour and allowing a less aggressive surgical approach for the patient [2]. 7-27\% of new breast cancers are treated with NAC [3]. Between $10 \%$ and $40 \%$ of patients, depending on tumour subtype, receiving NAC can have a pathologic complete response (pCR) to chemotherapy [4] as determined by the Miller-Payne grading system [5].

While mortality has decreased dramatically due to earlier diagnosis and advances in treatment, metastatic disease represents the main cause of breast cancer-related morbidity and death [6], and 
approximately $20 \%$ of breast cancers will experience metastatic relapse. Disease spread via circulating tumour cells (CTCs) in the bloodstream may explain how metastasis occurs [7, 8]. At present, enumeration of CTCs is limited in the clinical setting to predicting clinical outcome $[9,10]$. However, future potential applications include their use for both determining and monitoring efficacy of personalised treatment, and predicting and detecting metastases $[11,12]$. In order that the full prognostic and predictive power of CTCs is realised, there are a number of issues to examine in terms of limitations in how CTCs are defined, detected and isolated [9], as EpCAM-based detection excludes what is widely considered the most clinically relevant subsets of CTCs. The gold standard CellSearch ${ }^{\text {TM }}$ for CTC identification approved by U.S. Food and Drug Admistration (FDA) uses fluorescently labelled cytokeratin monoclonal antibodies, the nuclear stain DAPI, and the absence of staining by CD45 (pan-leukocyte stain), resulting in the overall selection of $\mathrm{EpCAM}^{+}, \mathrm{CD}^{+}, \mathrm{CD} 18^{+}, \mathrm{CD} 45^{-}$cells [9]. A major disadvantage of a number of CTC detection techniques is that they are dependent on capture based on epithelial marker expression, i.e. EpCAM and cytokeratins [13]. EpCAM is not a universal CTC biomarker [14] and therefore, detection is limited if expression has been downregulated due to epithelial mesenchymal transition (EMT) [15], while circulating tumour cells of mesenchymal origin are also not captured [16]. It is well recognised that CTCs are heterogeneous, with certain subgroups of CTCs harbouring higher metastatic potential. CTC clusters/microemboli have been associated with a worse clinical outcome in breast and lung cancer [17-19]. Current technologies underestimate CTC clusters because few specialized devices exist for the detection of CTC clusters and microemboli $[20,21]$.

The relationship between the presence of CTCs in the circulation and the response to NAC is currently an area of interest. If CTCs had the ability to predict those patients that have a complete pathological response, this could have a major impact on breast cancer treatment. A recent meta-analysis looking at the utility of CTCs assessed using the CellSearch ${ }^{T M}$ system in non-metastatic breast cancer patients receiving neoadjuvant chemotherapy did not find any correlation with CTC count and response to chemotherapy [22]. A second meta-analysis concluded that CTC count as measured by multiple devices had utility in predicting therapy response in breast cancer [23]. The isolation technologies and characterisation of CTCs is clearly recognised as a limitation in these studies.

This current study focussed on evaluation of all physical forms of CTCs using a non-marker based approach, ScreenCell (Paris, France), pre- and post-neoadjuvant chemotherapy for breast cancer in order to ascertain the utility of CTCs to predict response to neoadjuvant chemotherapy. The ScreenCell sizeselective method takes advantage of the larger size of CTCs compared with nucleated blood cells for isolation, with its circular pores of $7.5 \pm 0.36 \mu \mathrm{m}$ randomly distributed throughout the filter with a pore density of $1 \times 10^{5}$ pores $/ \mathrm{cm}^{2}$ [24]. It avoids the bias introduced by antibodies, and false negatives/positives associated with these methods. Response to chemotherapy was assessed using the Miller-Payne grading system [5] and radiological assessment. 


\section{Methods}

\section{Patient Recruitment}

Blood samples were obtained from 26 patients undergoing treatment for breast cancer at St. James's Hospital, Dublin 8, Ireland between 2015-2016. All patients received informed consent, and the study was approved by the St James's and AMNCH (Adelaide and Meath incorporating the National Children's Hospital) research ethics committee. Patients with a preoperative indication at multidisciplinary team discussion for neoadjuvant chemotherapy followed by surgery were recruited. Patients with Stage 4 disease were excluded. A $3 \mathrm{ml}$ blood sample was taken from each patient prior to the initiation of chemotherapy, and following completion of chemotherapy but prior to surgery. Clinicopathological data was collected for each patient including patient age, body mass index (BMI), receptor status, tumour grade, lymphovascular space invasion (LVI), clinical and pathological stage (TNM status) and pathological response (Miller-Payne grade) to chemotherapy. An Allred score was used to determine oestrogen and progesterone status. The Abbott Vysis system was used to assess HER2 status. The molecular subtype was recorded but a limitation of this is the ki-67 is not routinely done in our centre so the differentiation between luminal $A$ and $B$ was not always possible. The characteristics of these patients are shown in Table 1. In addition, a number of other blood parameters assessed as part of the routine clinical care including CA153 (if relevant), haemoglobin, haematocrit, white cell count and platelet count were recorded for analysis.

\section{Blood Processing}

Patient blood samples were obtained and stored in $\mathrm{K}_{2}$ EDTA tubes at $4 \llbracket \mathrm{C} .3 \mathrm{mls}$ of blood was placed in a $15 \mathrm{ml}$ falcon tube, combined with $4 \mathrm{ml} \mathrm{FC}_{2}$ buffer, inverted 3 times and incubated for 8 minutes at room temperature (RT). Blood was filtered through the ScreenCell device as per manufacturer's instructions, and $1.6 \mathrm{mls}$ PBS was also passed through the filter to remove any blood on the sides of the device.

The filter was detached from the device to enable downstream manipulation and the underside wiped with a PBS-soaked cotton bud to reduce the number of white blood cells trapped. The filter was placed on tissue paper and 50 $\mu$ PBS was drawn through twice by gentle application of pressure using tweezers on the metal O-ring. The filter was submerged in $3 \mathrm{ml} \mathrm{Histoclear} \mathrm{II,} \mathrm{and} \mathrm{detached} \mathrm{from} \mathrm{the} \mathrm{O-ring} \mathrm{using}$ curved-tipped callipers. The filter was placed on a slide and a small right angle cut on the upper left so the upper side of the filter could be identified easily later. The filter was submerged 3-4 times in $\mathrm{dH}_{2} \mathrm{O}$ to rinse off excess Histoclear II, and placed on a parafilm-wrapped slide, ensuring that there was no $\mathrm{dH}_{2} \mathrm{O}$ trapped between the filter and the parafilm.

\section{Giemsa Staining and imaging}


$200 \mu \mathrm{l}$ modified Giemsa was applied to the filter and incubated at RT for 10 minutes. Excess stain was removed using tissue paper, before the filter was placed on a clean parafilm-covered slide. $200 \mu \mathrm{l}$ buffer pH 6.8 was applied and incubated for 2 minutes at RT. Buffer was removed and the washing step was repeated, and the filter was submerged in $3 \mathrm{ml}$ fresh Histoclear II.

To prepare for imaging, $400 \mu$ Histoclear II was applied to a clean, parafilm-covered slide and the filter was placed on it. An additional $20 \mu \mathrm{l}$ Histoclear II was added, and a coverslip slowly lowered on the slide. Excess Histoclear was absorbed using tissue paper, and the coverslip was secured using clear varnish at the corners. The slides were stored in a humidified chamber and scanned using a NanoZoomer 2.0-RS (Hamamatsu Photonics KK, Japan) at 20X with 9 layer z-stacks of $2 \mu \mathrm{M}$ per stack.

\section{Statistical Analysis}

All data were analysed using SPSS 24.0 statistic software (SPSS Inc., Chicago, IL, USA). The associations between CTCs and clinical and pathological variables were evaluated with $\chi 2$, with $p<0.05$ indicating significance.

\section{Results}

\section{Clinicopathological Data}

26 patients were recruited into the study, blood samples were taken prior to neoadjuvant chemotherapy and post neoadjuvant chemotherapy. Breast cancer diagnosis was made following referral by imaging (mammography, ultrasound, magnetic resonance imaging (MRI)) and biopsy. Disease was staged and the presence of metastatic disease assessed via Computerised Tomography (CT)/Thorax, Abdomen, Pelvis (TAP) and bone scan. Clinicopathological details are presented in Table 1 and Table S1. The median age of the cohort was 46 (29-69) years. Median BMl for the cohort was 27 (18-38), with over $50 \%$ of the cohort in the overweight/obese category. $89 \%$ (23) of the patients were diagnosed with invasive ductal carcinoma (IDC) and $11 \%$ of patients (3) were diagnosed with invasive lobular carcinoma (ILC). Patients received neoadjuvant chemotherapy following discussion at a multidisciplinary team meeting. The majority of patients had locally advanced disease with no distant metastasis, while others had a triple positive or triple negative diagnosis with no lymph node metastasis diagnosis prior to treatment. The majority of patients were treated with the ACT chemotherapy regimen, which consists of doxorubicin (Adriamycin) and cyclophosphamide, followed by treatment with paclitaxel (taxane). Patients with human epidermal growth factor receptor $2\left(\right.$ HER2 ${ }^{+}$) tumours also received Herceptin ${ }^{\circledR} .1$ patient developed neuropathy and did not complete paclitaxel treatment. Response to neoadjuvant chemotherapy was assessed prior to surgery using ultrasound, mammography or MRI. The majority (17 $(65 \%))$ of our cohort expressed oestrogen receptor (ER) and progesterone receptor (PR) positive as displayed in Table 1 and Supplementary Table 1. Four (15\%) of the cohort expressed HER2 which was confirmed by fluorescence in situ hybridisation (FISH). The predominant molecular subtype in our cohort was $\mathrm{ER}^{+}, \mathrm{PR}^{+}$and HER2 ${ }^{-}$with $58 \%$ (15) of our cohort staining for this subtype. $8 \%$ were triple positive and 
$27 \%$ triple negative. Pathological stage was recorded post-surgery. Patient age, body mass index, tumour subtype, receptor status, molecular subtype, tumour grade, clinical stage, pathological stage, LVI, radiological response and pathological response (Miller-Payne grade) to chemotherapy are displayed in Table 1. (Insert Table 1)

\section{CTC identification and enumeration}

Modified Giemsa staining was used for the identification of CTCs on scanned images of the ScreenCell filters. Two pathologists reviewed the filters and identified CTCs on the basis of morphology, using the following criteria: intact cell, high nuclear:cytoplasmic ratio, hyperchromatic nucleus with coarse chromatin, and the presence of macro-nucleoli. CTC heterogeneity was observed with CTCs being identified as single cells (Figure 1A), doublets (Figure 1B) and clusters/microemboli (Figure 1C,1D). CTC clusters/microemboli are defined as $\geq 3$ CTCs [19] in a spatiotemporal pattern. CTCs were enumerated in the pre- and post- chemotherapy sample and classified according to the CellSearch ${ }^{\text {TM }}$ cut-off of $<5$ or $\geq 5$ CTCs; correlations with clinical parameters are shown in Table 1. Detailed CTC counts are displayed in Supplementary Table 1. As only $3 \mathrm{mls}$ of blood was used with the ScreenCell device, correlations were also assessed with the equivalent cut-off of 2 CTCs to correct for the volume used with the CellSearch ${ }^{\text {TM }}$ device (data not presented). Data was also analysed categorising patients as positive or negative for CTCs (data not presented). (Insert Figure 1)

\section{Correlation of CTCs with clinicopathological data}

Data for CTC counts are presented in Table 1 and individual counts are detailed in supplementary Table 1. At baseline, 4 patients were CTC-negative. 7 patients had 1-4 CTCs and 15 patients had $\geq 5$ CTCs as determined by Total CTC count in Supplementary Table 1. The median baseline number of CTCs was 7 (0-161). Post chemotherapy, 1 patient was CTC-negative, 8 patients had 1-4 CTCs and 17 patients had $\geq 5$ CTCs. The median post-chemotherapy number of CTCs was 9.5 (0-300).

No significant association was identified between the number of CTCs (categorised $<$ or $\geq 5$ CTCs as per the CellSearch ${ }^{\mathrm{TM}}$ studies) in the pre-chemotherapy or post-chemotherapy blood sample and clinical characteristics, such as patient age, receptor status, molecular subtype, tumour grade, disease type, clinical or pathological stage (incorporating tumour size and lymph node metastasis), LVI, radiological response or Miller Payne Grade (Table 1). A significant correlation was observed between BMI and pretreatment CTC count, $\mathrm{p}<0.05$.

CTC counts were also categorised using 2 CTCs as the cut-off (correcting for the blood volume used) and as positive/negative but no correlation was observed. 
CTC counts were correlated with corresponding blood parameters assessed on the same day as part of the routine work-up, including haemoglobin level, haematocrit, white cell count, CA153 if available and platelet count. No correlation was found between CTC count and any of these parameters (data not shown).

The change in total CTCs between the pre-and post-neoadjuvant chemotherapy samples was very variable between patients (Supplementary Figure 1), with some having a decrease of 61 CTCs while others had an increase of 270 CTCs. Overall, 13 (50\%) patients experienced an increase in total CTCs, 10 experienced a decrease and 2 had no change.

$65 \%$ of patients had a good response to neoadjuvant chemotherapy with a Miller Payne grade of 3 or more. Five patients (19\%) had a Miller Payne grade of 5 , or a complete pathological response to chemotherapy. This did not correlate with CTC counts, either pre- or post-chemotherapy or with the change in CTC numbers.

\section{Correlation of CTC clusters with clinicopathological data}

In addition to total CTC counts, the number of CTC clusters were also evaluated and assessed independently for clinical significance. No association was found between the total number of CTC clusters in a pre- or post- chemotherapy sample (also assessed as positive or negative for clusters) and the clinical factors of patient age, BMI, tumour subtype, receptor status, tumour grade, clinical or pathological tumour stage, LVI, radiological response or Miller Payne Grade. However, if we categorise clusters as $<$ or $\geq 2$ we do observe a correlation pre-treatment counts and BMI, $p<0.05$. The number of cells in each cluster was also counted as displayed in supplementary Table 1 but no correlation in this total cell count was observed with clinical parameters.

In relation to other blood parameters, no correlation was seen between CTC cluster counts and haemoglobin level, haematocrit, white cell count, CA153 if available and platelet count.

At baseline, 13 patients were negative for CTC clusters, 5 patients had 1-4 CTC clusters and 8 patients had $\geq 5$ CTC clusters. The median baseline number of clusters was 0.5 (0-40). The change in CTC clusters was again very variable between patients (Supplementary Figure 2). Post chemotherapy, 10 patients were negative for CTC clusters, 9 patients had $<5$ CTC clusters and 7 patients had $>5$ CTC clusters. The median post-chemotherapy CTC cluster value was 1.5 (0-26). Overall, 11 (42\%) patients experienced an increase in CTC clusters, 10 had a decrease in CTC clusters and 5 remained unchanged.

\section{Correlation of CTCs with clinical outcome}

We were unable to assess the prognostic potential of the CTC counts in our study to date as very few of the patients have presented with a recurrence. Only observational data can be presented at this stage. As outlined in Supplementary Table 1, following a 3-year follow-up, 21 patients are currently alive with no 
evidence of disease (ANED), 3 patients have had a recurrence (AWD) and 2 patients have died of disease (DOD). Of the 2 patients that died of disease, both had an increase in CTCs following chemotherapy, 1 had no CTCs at baseline. Of the 3 patients that had a recurrence, 1 had a decrease in CTCs post chemo, 1 had no change in CTCs between the pre and post chemo sample and the $3^{\text {rd }}$ had an increase in CTCs (in particular in clusters). At this stage it would seem that the presence of CTCs post chemotherapy will have some prognostic potential, but it is not possible to reliably say this at this point. It is our intention to review this data for a 5-year follow-up and beyond if necessary.

\section{Discussion}

This study did not show any benefit for CTC counts prior to treatment or prior to surgery in assessing pathological response to neoadjuvant chemotherapy in breast cancer patients. It is likely that more in depth analysis of CTCs will unlock their true potential in the clinic but currently many limitations exist in terms of their isolation and characterisation.

CTCs were detected in $85 \%$ of patients in this study prior to treatment, which is higher than some of the quoted studies in the literature which vary from $31 \%$ to $61 \%[22,23]$. However, many of the published studies used the CellSearch ${ }^{\text {TM }}$ system, which we know underestimates CTC numbers due to its reliance on the presence of EpCAM. In addition, some meta-analyses published [22, 23] have included early breast cancer patients whereas in this study we focussed on those with locally advanced disease (including some triple positive/negative with NO disease $n=6$ ) who were undergoing NAC followed by surgery, a cohort we would expect to be higher CTC traffickers. The GeparQuattro trial did focus on a neoadjuvant cohort using the CellSearch ${ }^{\mathrm{TM}}$ system and found prognostic ability in pre-treatment CTC counts for HER2 positive and triple negative patients using a cut-off of 2 CTCs but similar to our findings this prognostic ability was independent of the primary tumour response [25]. The patient population selected and the ScreenCell isolation device used may explain the higher percentage of patients having CTCs at the outset.

Significant heterogeneity was observed in the CTC phenotypes isolated, single cells, doublets and clusters. At baseline, clusters were isolated in $50 \%$ of our patient cohort. This is slightly higher than recently reported by Vetter et al, who found 35\% of their cohort had clusters present prior to treatment [26], using the Parsortix microfluidic device. Studies using the CellSearch ${ }^{\text {TM }}$ system report cluster rates around $20 \%$ [27]. Current technologies significantly under-call the number of CTC clusters because few specialised devices exist for their detection. The definition of clusters also varies in the literature from $>1$ CTC to $>2$ or 3 cells [19]. In this study, we define clusters as $\geq 3$ CTCs but we have also conducted analyses using the other cut-offs of $>1$ cell and we did not find any significance with our clinicopathological details or response to neoadjuvant chemotherapy. Clusters are more aggressive than single CTCs $[18,19]$ and a lot of effort is now focussed on methods for isolation and characterisation of CTC clusters $[20,21]$. We have previously reported the importance of platelets in cancer metastasis, which are a major component of these clusters and microemboli [28] and may explain the increased aggressiveness observed. In addition, we have shown that the platelet cloak can inhibit immune surveillance by NK cells enabling the CTCs to establish metastasis [29]. 
We did not observe any relationship between CTC counts and clinicopathological details such as patient age, receptor status, tumour grade, disease type, tumour size, LVI, lymph node metastasis radiological response or Miller Payne Grade for our patient cohort. We did see a correlation between BMI and pretreatment CTC counts with higher BMI patients having a higher count. BMI has been shown to mediate the prognostic significance of CTCs in inflammatory breast cancer [30]. In a recent publication, patientderived xenograft (PDX) model, tumours grown in the presence of obesity-altered adipose stem cells in $\mathrm{SCID} /$ beige mice had increased circulating $\mathrm{HLA} 1^{+}$human cells as well as increased numbers of $\mathrm{CD} 44^{+} \mathrm{CD} 24^{-}$cancer stem cells in the peripheral blood, the authors concluded leptin produced by obesityaltered adipose stem cells promotes metastasis. Others have found a negative association with $\mathrm{BMI}$ and CTC counts using the CellSearch device [31,32]. Further work is needed to assess this correlation between CTCs and BMI. Most studies including two meta-analyses [22, 23], did not observe any correlation with clinicopathological details but they did find CTC counts to have prognostic ability. The prognostic potential of CTC counts in our study has not yet been statistically assessed due to the low number of patients, presenting with recurrences but it is our intention to carry out a 5 year follow up on these patients. It does, however, seem like the presence of CTCs post chemotherapy will have some prognostic potential.

Some studies have assessed correlation of CTC counts with complete pathological response. The method of measuring the PCR is not detailed in all studies. In this study, the CTC count before and after chemotherapy was correlated with radiological findings and also to the pathological score of Miller Payne grading. There was no correlation between CTC counts and this score, $19 \%$ of the patients in our cohort had a pCR and all of these still had CTCs following neoadjuvant chemotherapy. Other studies report a decline in CTC counts post neoadjuvant treatment [33] while some report an increase [34]. While CTCs were present post treatment, we do not know the metastatic potential of these CTCs and this is needed to unlock the true potential of CTCs in the clinic. In our study, we observed an increase of $58 \%$ in CTCs and $42 \%$ in CTC clusters in the patients post chemotherapy which is similar to the observations in a prostate cancer study where $42 \%$ of patients had an increase in CTCs post treatment [35]. There may be many reasons for the increase in CTC counts/clusters observed post treatment. This may be explained by the rate at which the various tumour subtypes shed tumour cells into the circulation. The chemotherapy may have caused the vessels to become leaky and shed more cells into the vasculature. It may be that the chemotherapy has selected for a clonal population of stem like cells that have survived the chemotherapy. Other mechanisms that may explain this increased number include autophagy, aniokis, expansion of pro-metastatic variants or a potential drive towards dormancy, which would be of interest for future studies. Clearly, further work is needed on assessing the viability and molecular characterisation of the CTCs that remain post treatment. We hypothesise that CTC clusters are more likely to be viable than single CTCs. While these reasons may explain the findings in the cohort of patients who still have residual disease, it does not explain the situation for those who have had a complete pathological response. It suggests a differential response between the primary tumour and the CTCs and is similar to the findings in the Geparquattro trial [18]. Follow-up of these patients is needed to determine the long-term significance of these CTCs. One study has reported the detection of CTCs 8-22

Page $10 / 19$ 
years out from treatment, despite no clinical evidence of disease [36]. It is not known if this represents tumour dormancy and persistence of disseminated disease in the bone marrow as suggested by some investigators $[37,38]$ or whether a proportion of these patients will go on to develop metastatic disease. This stresses the need for molecular characterisation and long term follow up of patients.

Many groups are now focussing on characterising and dissecting the metastatic potential of CTCs. Our group has established a CTC-5 program which allows us to merge a morphology image of the isolated CTCs with an immunofluorescent profile for the same cells which will give us a better insight into their biology (manuscript in prep). A focus on single cell genomics and cluster dissection may reveal mechanisms of how the cells in a cluster co-operate and metastasise, enabling CTCs to have a more proactive role in the clinic. Unlocking the full potential of the liquid biopsy to monitor treatment response in breast cancer will allow us ultimately to deliver a more personalised medicine approach for cancer patients, improving therapeutic outcomes.

\section{Conclusions}

CTC enumeration is not sufficient to predict which breast cancer patients should undergo surgery following neoadjuvant chemotherapy. Additional characterisation of CTCs and CTC clusters is needed to assess the true potential of CTCs in this cohort of patients. Long-term follow-up of patients is needed to assess the significance of CTC counts.

\section{Abbreviations}

AMNCH: Adelaide and Meath incorporating the National Children's Hospital

ANED: Alive with no evidence of disease

AWD: Alive with disease

BL: Baseline

BMl: Body mass index

CK: Cytokeratin

CT: Computerised Tomography

CTCs: Circulating tumour cells

DOD: Died of disease

EMT: Epithelial-mesenchymal transition

EpCAM: Epithelial cell adhesion molecule 
ER: Oestrogen receptor

FISH: Fluorescence in situ hybridisation

HER2: Human epidermal growth factor receptor 2

HR: Hazard ratio

IDC: Invasive ductal carcinoma

ILC: Invasive lobular carcinoma

MRI: Magnetic resource imaging

NAC: Neoadjuvant Chemotherapy

OS: Overall survival

pCR: Pathological complete response

PR: Progesterone receptor

RT: Room temperature

TNBC: Triple-negative breast cancer

\section{Declarations}

\section{Ethics approval and consent to participate}

The study was approved by the St James's and AMNCH (Adelaide and Meath incorporating the National Children's Hospital) research ethics committee. All included patients provided written informed consent for participation.

\section{Consent for publication}

All included patients provided written informed consent; no patient identifier is included in the publication.

\section{Availability of data and material}

The datasets used and analysed during the current study are available from the corresponding author on request. 


\section{Competing interests}

The authors declare that they have no competing interests.

\section{Funding}

This study was funded by a Health Research Board Clinician Scientist Award to Prof John O'Leary. The study was also supported by an Innovation Partnership Fund from Enterprise Ireland, which is also cofunded by the European Regional Development Fund (ERDF) under Ireland's European Structural and Investment Funds Programmes 2014-2020.

\section{Authors' contributions}

SOT, CS, BF, JK and JOL were involved in the conception and design of the study took part in acquisition of data, analysis and interpretation of data, and drafting and reviewing of the manuscript. YH was involved in acquisition of data, analysis and interpretation of the data and drafting and reviewing of the manuscript. MF, BM, MW, MG, CM, TK were involved in the interpretation of the data and manuscript revision. $\mathrm{COB}$ was involved in optimising scanning of all images. $\mathrm{CR}$ was responsible for consent and follow up of patients. $A B$ was involved in processing of samples and manuscript revision. DM was involved in data analysis and interpretation of the data and characterisation of CTCs. EC and SMcG were responsible for identification of patients, recruitment, interpretation of the data and manuscript revision.

\section{Acknowledgements}

We would like to thank all the patients that took part in this study and are very grateful to them. We thank the research nurses and the medical oncologists at St. James's Hospital for their invaluable work in the inclusion of patients during the study period.

\section{References}

1. Bray F, Ferlay J, Soerjomataram I, Siegel RL, Torre LA, Jemal A: Global cancer statistics 2018: GLOBOCAN estimates of incidence and mortality worldwide for 36 cancers in 185 countries. $C A$ Cancer J Clin 2018, 68(6):394-424. 
2. Kaufmann M, von Minckwitz G, Bear HD, Buzdar A, McGale P, Bonnefoi H, Colleoni M, Denkert C, Eiermann W, Jackesz R et al: Recommendations from an international expert panel on the use of neoadjuvant (primary) systemic treatment of operable breast cancer: new perspectives 2006. Ann Oncol 2007, 18(12):1927-1934.

3. Vaidya JS, Massarut S, Vaidya HJ, Alexander EC, Richards T, Caris JA, Sirohi B, Tobias JS: Rethinking neoadjuvant chemotherapy for breast cancer. BMJ 2018, 360:j5913.

4. Houssami N, Macaskill P, von Minckwitz G, Marinovich ML, Mamounas E: Meta-analysis of the association of breast cancer subtype and pathologic complete response to neoadjuvant chemotherapy. Eur J Cancer 2012, 48(18):3342-3354.

5. Ogston KN, Miller ID, Payne S, Hutcheon AW, Sarkar TK, Smith I, Schofield A, Heys SD: A new histological grading system to assess response of breast cancers to primary chemotherapy: prognostic significance and survival. Breast 2003, 12(5):320-327.

6. Jemal A, Bray F, Center MM, Ferlay J, Ward E, Forman D: Global cancer statistics. CA Cancer J Clin 2011, 61(2):69-90.

7. Giuliano M, Giordano A, Jackson S, De Giorgi U, Mego M, Cohen EN, Gao H, Anfossi S, Handy BC, Ueno NT et al: Circulating tumor cells as early predictors of metastatic spread in breast cancer patients with limited metastatic dissemination. Breast Cancer Res 2014, 16(5):440.

8. Nguyen DX, Bos PD, Massague J: Metastasis: from dissemination to organ-specific colonization. Nat Rev Cancer 2009, 9(4):274-284.

9. Millner LM, Linder MW, Valdes R, Jr.: Circulating tumor cells: a review of present methods and the need to identify heterogeneous phenotypes. Ann Clin Lab Sci 2013, 43(3):295-304.

10. Heitzer E, Haque IS, Roberts CES, Speicher MR: Current and future perspectives of liquid biopsies in genomics-driven oncology. Nat Rev Genet 2018.

11. Selli C, Dixon JM, Sims AH: Accurate prediction of response to endocrine therapy in breast cancer patients: current and future biomarkers. Breast Cancer Res 2016, 18(1):118.

12. Hwang WL, Pleskow HM, Miyamoto DT: Molecular analysis of circulating tumors cells: Biomarkers beyond enumeration. Adv Drug Deliv Rev 2018, 125:122-131.

13. Krebs MG, Hou JM, Ward TH, Blackhall FH, Dive C: Circulating tumour cells: their utility in cancer management and predicting outcomes. Ther Adv Med Oncol 2010, 2(6):351-365.

14. Gupta V, Jafferji I, Garza M, Melnikova VO, Hasegawa DK, Pethig R, Davis DW: ApoStream0, a new dielectrophoretic device for antibody independent isolation and recovery of viable cancer cells from blood. Biomicrofluidics 2012, 6(2):24133.

15. Gorges TM, Tinhofer I, Drosch M, Rose L, Zollner TM, Krahn T, von Ahsen O: Circulating tumour cells escape from EpCAM-based detection due to epithelial-to-mesenchymal transition. BMC Cancer 2012, 12:178.

16. Gabriel MT, Calleja LR, Chalopin A, Ory B, Heymann D: Circulating Tumor Cells: A Review of NonEpCAM-Based Approaches for Cell Enrichment and Isolation. Clin Chem 2016, 62(4):571-581. 
17. Mu Z, Wang C, Ye Z, Austin L, Civan J, Hyslop T, Palazzo JP, Jaslow R, Li B, Myers RE et al: Prospective assessment of the prognostic value of circulating tumor cells and their clusters in patients with advanced-stage breast cancer. Breast Cancer Res Treat 2015, 154(3):563-571.

18. Aceto N, Bardia A, Miyamoto DT, Donaldson MC, Wittner BS, Spencer JA, Yu M, Pely A, Engstrom A, Zhu $\mathrm{H}$ et al: Circulating tumor cell clusters are oligoclonal precursors of breast cancer metastasis. Cell 2014, 158(5):1110-1122.

19. Hou JM, Krebs MG, Lancashire L, Sloane R, Backen A, Swain RK, Priest LJ, Greystoke A, Zhou C, Morris $\mathrm{K}$ et al: Clinical significance and molecular characteristics of circulating tumor cells and circulating tumor microemboli in patients with small-cell lung cancer. J Clin Oncol 2012, 30(5):525532.

20. Jiang X, Wong KHK, Khankhel AH, Zeinali M, Reategui E, Phillips MJ, Luo X, Aceto N, Fachin F, Hoang AN et al: Microfluidic isolation of platelet-covered circulating tumor cells. Lab Chip 2017, 17(20):3498-3503.

21. Sarioglu AF, Aceto N, Kojic N, Donaldson MC, Zeinali M, Hamza B, Engstrom A, Zhu H, Sundaresan TK, Miyamoto DT et al: A microfluidic device for label-free, physical capture of circulating tumor cell clusters. Nat Methods 2015, 12(7):685-691.

22. Bidard FC, Michiels S, Riethdorf S, Mueller V, Esserman LJ, Lucci A, Naume B, Horiguchi J, GisbertCriado R, Sleijfer S et al: Circulating Tumor Cells in Breast Cancer Patients Treated by Neoadjuvant Chemotherapy: A Meta-analysis. J Natl Cancer Inst 2018, 110(6):560-567.

23. Yan WT, Cui X, Chen Q, Li YF, Cui YH, Wang Y, Jiang J: Circulating tumor cell status monitors the treatment responses in breast cancer patients: a meta-analysis. Sci Rep 2017, 7:43464.

24. Desitter I, Guerrouahen BS, Benali-Furet N, Wechsler J, Janne PA, Kuang Y, Yanagita M, Wang L, Berkowitz JA, Distel RJ et al: A new device for rapid isolation by size and characterization of rare circulating tumor cells. Anticancer Res 2011, 31(2):427-441.

25. Riethdorf S, Muller V, Loibl S, Nekljudova V, Weber K, Huober J, Fehm T, Schrader I, Hilfrich J, Holms F et al: Prognostic Impact of Circulating Tumor Cells for Breast Cancer Patients Treated in the Neoadjuvant "Geparquattro" Trial. Clin Cancer Res 2017, 23(18):5384-5393.

26. Vetter M, Landin J, Szczerba BM, Castro-Giner F, Gkountela S, Donato C, Krol I, Scherrer R, Balmelli C, Malinovska A et al: Denosumab treatment is associated with the absence of circulating tumor cells in patients with breast cancer. Breast Cancer Res 2018, 20(1):141.

27. Larsson AM, Jansson S, Bendahl PO, Levin Tykjaer Jorgensen C, Loman N, Graffman C, Lundgren L, Aaltonen K, Ryden L: Longitudinal enumeration and cluster evaluation of circulating tumor cells improve prognostication for patients with newly diagnosed metastatic breast cancer in a prospective observational trial. Breast Cancer Res 2018, 20(1):48.

28. Egan K, Crowley D, Smyth P, O'Toole S, Spillane C, Martin C, Gallagher M, Canney A, Norris L, Conlon $\mathrm{N}$ et al: Platelet adhesion and degranulation induce pro-survival and pro-angiogenic signalling in ovarian cancer cells. PLoS One 2011, 6(10):e26125. 
29. Cluxton CD, Spillane C, O'Toole SA, Sheils O, Gardiner CM, O'Leary JJ: Suppression of Natural Killer cell NKG2D and CD226 anti-tumour cascades by platelet cloaked cancer cells: Implications for the metastatic cascade. PLoS One 2019, 14(3):e0211538.

30. Fayanju OM, Hall CS, Bauldry JB, Karhade M, Valad LM, Kuerer HM, DeSnyder SM, Barcenas CH, Lucci A: Body mass index mediates the prognostic significance of circulating tumor cells in inflammatory breast cancer. Am J Surg 2017, 214(4):666-671.

31. Sabol RA, Bowles AC, Cote A, Wise R, O'Donnell B, Matossian MD, Hossain FM, Burks HE, Del Valle L, Miele $L$ et al: Leptin produced by obesity-altered adipose stem cells promotes metastasis but not tumorigenesis of triple-negative breast cancer in orthotopic xenograft and patient-derived xenograft models. Breast Cancer Res 2019, 21(1):67.

32. Lohmann AE, Dowling RJO, Ennis M, Amir E, Elser C, Brezden-Masley C, Vandenberg T, Lee E, Fazaee $\mathrm{K}$, Stambolic $\mathrm{V}$ et al: Association of Metabolic, Inflammatory, and Tumor Markers With Circulating Tumor Cells in Metastatic Breast Cancer. JNCI Cancer Spectr 2018, 2(2):pky028.

33. Martin M, Custodio S, de Las Casas ML, Garcia-Saenz JA, de la Torre JC, Bellon-Cano JM, LopezTarruella S, Vidaurreta-Lazaro M, de la Orden V, Jerez $Y$ et al: Circulating tumor cells following first chemotherapy cycle: an early and strong predictor of outcome in patients with metastatic breast cancer. Oncologist 2013, 18(8):917-923.

34. Rack B, Schindlbeck C, Juckstock J, Andergassen U, Hepp P, Zwingers T, Friedl TW, Lorenz R, Tesch H, Fasching PA et al: Circulating tumor cells predict survival in early average-to-high risk breast cancer patients. J Natl Cancer Inst 2014, 106(5).

35. Lorente D, Olmos D, Mateo J, Dolling D, Bianchini D, Seed G, Flohr P, Crespo M, Figueiredo I, Miranda $S$ et al: Circulating tumour cell increase as a biomarker of disease progression in metastatic castration-resistant prostate cancer patients with low baseline CTC counts. Ann Oncol 2018, 29(7):1554-1560.

36. Meng S, Tripathy D, Frenkel EP, Shete S, Naftalis EZ, Huth JF, Beitsch PD, Leitch M, Hoover S, Euhus D et al: Circulating tumor cells in patients with breast cancer dormancy. Clin Cancer Res 2004, 10(24):8152-8162.

37. Braun S, Kentenich C, Janni W, Hepp F, de Waal J, Willgeroth F, Sommer H, Pantel K: Lack of effect of adjuvant chemotherapy on the elimination of single dormant tumor cells in bone marrow of high-risk breast cancer patients. J Clin Oncol 2000, 18(1):80-86.

38. Muller V, Stahmann N, Riethdorf S, Rau T, Zabel T, Goetz A, Janicke F, Pantel K: Circulating tumor cells in breast cancer: correlation to bone marrow micrometastases, heterogeneous response to systemic therapy and low proliferative activity. Clin Cancer Res 2005, 11(10):3678-3685.

\section{Tables}

Table 1. Association between pre-chemotherapy and post-chemotherapy CTC counts and clinical characteristics. 


\begin{tabular}{|c|c|c|c|c|c|c|c|}
\hline \multirow[t]{2}{*}{ Characteristics } & \multirow[t]{2}{*}{ Patients n (\%) } & \multirow{2}{*}{\multicolumn{2}{|c|}{$\begin{array}{l}\text { Pre-chemo CTCs } \\
\text { Patients n (\%) } \\
<5\end{array}$}} & \multirow[t]{3}{*}{ P Value } & \multicolumn{2}{|c|}{$\begin{array}{l}\text { Post-chemo CTCs } \\
\text { Patients n (\%) }\end{array}$} & \multirow[t]{2}{*}{$\begin{array}{c}\mathbf{P} \\
\text { value }\end{array}$} \\
\hline & & & & & & & \\
\hline Patient Cohort & $26(100.0 \%)$ & $11(42 \%)$ & $\begin{array}{l}15 \\
(58 \%)\end{array}$ & & $9(35 \%)$ & $\begin{array}{l}17 \\
(65 \%)\end{array}$ & \\
\hline \multicolumn{8}{|c|}{ Age (median 46 years) } \\
\hline$<46$ & $13(50.0 \%)$ & 5 (19.2\%) & $\begin{array}{l}8 \\
(30.8 \%)\end{array}$ & 0.691 & $\begin{array}{l}3 \\
(11.5 \%)\end{array}$ & $\begin{array}{l}9 \\
(34.6 \%)\end{array}$ & 0.68 \\
\hline$\geq 46$ & $13(50.0 \%)$ & $6(23.1 \%)$ & $\begin{array}{l}7 \\
(26.9 \%)\end{array}$ & & $\begin{array}{l}5 \\
(19.2 \%)\end{array}$ & $\begin{array}{l}8 \\
(30.8 \%)\end{array}$ & \\
\hline \multicolumn{8}{|l|}{ BMI } \\
\hline$<25$ & $12(46.2 \%)$ & $8(30.8 \%)$ & $\begin{array}{l}4 \\
(15.4 \%)\end{array}$ & $0.02 *$ & $\begin{array}{l}4 \\
(15.4 \%)\end{array}$ & $\begin{array}{l}8 \\
(30.8 \%)\end{array}$ & 0.899 \\
\hline$\geq 25$ & $14(53.8 \%)$ & $3(11.5 \%)$ & $\begin{array}{l}11 \\
(42.3 \%)\end{array}$ & & $\begin{array}{l}5 \\
(11.5 \%)\end{array}$ & $\begin{array}{l}9 \\
(34.6 \%)\end{array}$ & \\
\hline \multicolumn{8}{|l|}{ Subtype } \\
\hline Ductal & $23(88.5 \%)$ & 9 (34.6\%) & $\begin{array}{l}14 \\
(53.8 \%)\end{array}$ & 0.364 & $\begin{array}{l}7 \\
(26.9 \%)\end{array}$ & $\begin{array}{l}16 \\
(61.5 \%)\end{array}$ & 0.215 \\
\hline Lobular & $3(11.5 \%)$ & $2(7.7 \%)$ & $\begin{array}{l}1 \\
(3.8 \%)\end{array}$ & & $\begin{array}{l}2 \\
(7.7 \%)\end{array}$ & $\begin{array}{c}1 \\
(3.8 \%)\end{array}$ & \\
\hline \multicolumn{8}{|l|}{ Receptor Status } \\
\hline $\mathrm{ER}+/ \mathrm{PR}+$ & 17 (65.4\%) & 8 (30.8\%) & $\begin{array}{l}9 \\
(34.6 \%)\end{array}$ & 0.286 & $\begin{array}{l}7 \\
(26.9 \%)\end{array}$ & $\begin{array}{l}10 \\
(38.5 \%)\end{array}$ & 0.139 \\
\hline ER-/PR- & $8(30.8 \%)$ & $2(7.7 \%)$ & $\begin{array}{l}6 \\
(23.1 \%)\end{array}$ & & $\begin{array}{l}1 \\
(3.8 \%)\end{array}$ & $\begin{array}{l}7 \\
(26.9 \%)\end{array}$ & \\
\hline $\mathrm{ER}+/ \mathrm{PR}-$ & $1(3.8 \%)$ & $1(3.8 \%)$ & $\begin{array}{l}0 \\
(0.0 \%)\end{array}$ & & $\begin{array}{l}1 \\
(3.8 \%)\end{array}$ & $\begin{array}{l}0 \\
(0.0 \%)\end{array}$ & \\
\hline HER2+ & $4(15.4 \%)$ & $2(7.7 \%)$ & $\begin{array}{l}2 \\
(7.7 \%)\end{array}$ & 0.735 & $\begin{array}{l}2 \\
(7.7 \%)\end{array}$ & $\begin{array}{l}2 \\
(7.7 \%)\end{array}$ & 0.482 \\
\hline HER2- & $22(84.6 \%)$ & 9 (34.6\%) & $\begin{array}{l}13 \\
(50.0 \%)\end{array}$ & & $\begin{array}{l}7 \\
(26.9 \%)\end{array}$ & $\begin{array}{l}15 \\
(57.7 \%)\end{array}$ & \\
\hline TNBC & 7 (26.9\%) & $2(7.7 \%)$ & $\begin{array}{l}5 \\
(19.2 \%)\end{array}$ & 0.39 & $\begin{array}{l}1 \\
(3.8 \%)\end{array}$ & $\begin{array}{l}6 \\
(23.1 \%)\end{array}$ & 0.186 \\
\hline Non TNBC & $19(73.1 \%)$ & $9(34.6 \%)$ & $\begin{array}{l}10 \\
(38.5 \%)\end{array}$ & & $\begin{array}{l}8 \\
(30.8 \%)\end{array}$ & $\begin{array}{l}11 \\
(42.3 \%)\end{array}$ & \\
\hline \multicolumn{8}{|l|}{ Molecular Subtype } \\
\hline Luminal-A-like & $15(57.7 \%)$ & 7 (26.9\%) & $\begin{array}{l}8 \\
(30.8 \%)\end{array}$ & 0.548 & $\begin{array}{l}6 \\
(23.1 \%)\end{array}$ & $\begin{array}{l}9 \\
(34.6 \%)\end{array}$ & 0.339 \\
\hline Luminal-B (Her2+) & $3(11.5 \%)$ & $2(7.7 \%)$ & $\begin{array}{l}1 \\
(3.8 \%)\end{array}$ & & $\begin{array}{l}2 \\
(7.7 \%)\end{array}$ & $\begin{array}{l}1 \\
(3.8 \%)\end{array}$ & \\
\hline Basal like/TNBC & $7(26.9 \%)$ & $2(7.7 \%)$ & $\begin{array}{l}5 \\
(19.2 \%)\end{array}$ & & $\begin{array}{l}1 \\
(3.8 \%)\end{array}$ & $\begin{array}{l}6 \\
(23.1 \%)\end{array}$ & \\
\hline Her2 Enriched & $1(3.8 \%)$ & $0(0.0 \%)$ & $\begin{array}{l}1 \\
(3.8 \%)\end{array}$ & & $\begin{array}{l}0 \\
(0.0 \%)\end{array}$ & $\begin{array}{l}1 \\
(3.8 \%)\end{array}$ & \\
\hline \multicolumn{8}{|l|}{ Grade } \\
\hline Grade 1 & $2(7.7 \%)$ & $0(0.0 \%)$ & $\begin{array}{l}2 \\
(7.7 \%)\end{array}$ & 0.155 & $\begin{array}{l}0 \\
(0.0 \%)\end{array}$ & $\begin{array}{l}2 \\
(7.7 \%)\end{array}$ & 0.372 \\
\hline Grade 2 & 16 (61.5\%) & 9 (34.6\%) & $\begin{array}{l}7 \\
(26.9 \%)\end{array}$ & & $\begin{array}{l}7 \\
(26.9 \%)\end{array}$ & $\begin{array}{l}9 \\
(34.6 \%)\end{array}$ & \\
\hline Grade 3 & $8(30.8 \%)$ & $2(7.7 \%)$ & $\begin{array}{l}6 \\
(23.1 \%)\end{array}$ & & $\begin{array}{l}2 \\
(7.7 \%)\end{array}$ & $\begin{array}{l}6 \\
(23.1 \%)\end{array}$ & \\
\hline \multicolumn{8}{|l|}{ Clinical Stage } \\
\hline T1 & $2(7.7 \%)$ & $1(3.8 \%)$ & $\begin{array}{l}1 \\
(3.8 \%)\end{array}$ & 0.763 & $\begin{array}{l}0 \\
(0.0 \%)\end{array}$ & $\begin{array}{l}2 \\
(7.7 \%)\end{array}$ & 0.177 \\
\hline T2 & 10 (38.5\%) & 5 (19.2\%) & 5 & & 2 & 8 & \\
\hline
\end{tabular}




\begin{tabular}{|c|c|c|c|c|c|c|c|}
\hline & & & $(19.2 \%)$ & & $(7.7 \%)$ & $(30.8 \%)$ & \\
\hline T3 & $14(53.8 \%)$ & $5(19.2 \%)$ & $\begin{array}{l}9 \\
(34.6 \%)\end{array}$ & & $\begin{array}{l}7 \\
(26.9 \%)\end{array}$ & $\begin{array}{l}7 \\
(26.9 \%)\end{array}$ & \\
\hline \multicolumn{8}{|c|}{ Lymph Node Mets Pre } \\
\hline Yes & $20(76.9 \%)$ & $8(30.8 \%)$ & $\begin{array}{l}12 \\
(46.2 \%)\end{array}$ & 0.664 & $\begin{array}{l}8 \\
(30.8 \%)\end{array}$ & $\begin{array}{l}12 \\
(46.2 \%)\end{array}$ & 0.292 \\
\hline Not identified & $6(23.1 \%)$ & $3(11.5 \%)$ & 3 & & $\begin{array}{l}1 \\
(3.8 \%)\end{array}$ & $\begin{array}{l}5 \\
(19.2 \%)\end{array}$ & \\
\hline \multicolumn{8}{|c|}{ Radiological Response } \\
\hline No response & $1(3.8 \%)$ & $1(3.8 \%)$ & $\begin{array}{l}0 \\
(0.0 \%)\end{array}$ & 0.274 & $\begin{array}{l}0 \\
(0.0 \%)\end{array}$ & $\begin{array}{l}1 \\
(3.8 \%)\end{array}$ & 0.674 \\
\hline Partial & $18(69.2 \%)$ & $6(23.1 \%)$ & $\begin{array}{l}12 \\
(46.2 \%)\end{array}$ & & $\begin{array}{l}7 \\
\text { (26.9\%) }\end{array}$ & $\begin{array}{l}11 \\
(42.3 \%)\end{array}$ & \\
\hline Complete & 7 (26.9\%) & $4(15.4 \%)$ & $\begin{array}{l}3 \\
(11.5 \%)\end{array}$ & & $\begin{array}{l}2 \\
(7.7 \%)\end{array}$ & $\begin{array}{l}5 \\
(19.2 \%)\end{array}$ & \\
\hline \multicolumn{8}{|c|}{ Pathological Stage } \\
\hline Tis,T0-T1 & $16(61.5 \%)$ & $6(23.1 \%)$ & $\begin{array}{l}10 \\
(38.5 \%)\end{array}$ & 0.53 & $\begin{array}{l}4 \\
(15.4 \%)\end{array}$ & $\begin{array}{l}12 \\
(46.2 \%)\end{array}$ & 0.192 \\
\hline T2-T3 & $10(38.5 \%)$ & $5(19.2 \%)$ & $\begin{array}{l}5 \\
(19.2 \%)\end{array}$ & & $\begin{array}{l}5 \\
(19.2 \%)\end{array}$ & $\begin{array}{c}5 \\
(11.5 \%)\end{array}$ & \\
\hline \multicolumn{8}{|c|}{ Lymph Node Metastasis Path } \\
\hline Yes & $16(61.5 \%)$ & 7 (26.9\%) & $\begin{array}{l}9 \\
(34.6 \%)\end{array}$ & 0.851 & $\begin{array}{l}6 \\
(23.1 \%)\end{array}$ & $\begin{array}{l}10 \\
(38.5 \%)\end{array}$ & 0.696 \\
\hline Not identified & $10(38.5 \%)$ & $4(15.4 \%)$ & $\begin{array}{l}6 \\
(23.1 \%)\end{array}$ & & $\begin{array}{l}3 \\
(11.5 \%)\end{array}$ & $\begin{array}{l}7 \\
(26.9 \%)\end{array}$ & \\
\hline \multicolumn{8}{|l|}{ LVI } \\
\hline Yes & $6(23.1 \%)$ & $4(15.4 \%)$ & $\begin{array}{l}2 \\
(7.7 \%)\end{array}$ & 0.285 & $\begin{array}{l}3 \\
(11.5 \%)\end{array}$ & $\begin{array}{l}3 \\
(11.5 \%)\end{array}$ & 0.574 \\
\hline $\mathrm{NI}$ & $15(57.7 \%)$ & $6(23.1 \%)$ & $\begin{array}{l}9 \\
(34.6 \%)\end{array}$ & & $\begin{array}{l}4 \\
(15.4 \%)\end{array}$ & $\begin{array}{l}11 \\
(42.3 \%)\end{array}$ & \\
\hline NA & $5(19.2 \%)$ & $1(3.8 \%)$ & $\begin{array}{l}4 \\
(15.4 \%)\end{array}$ & & $\begin{array}{l}2 \\
(7.7 \%)\end{array}$ & $\begin{array}{l}3 \\
(11.5 \%)\end{array}$ & \\
\hline \multicolumn{8}{|c|}{ Miller Payne Grade } \\
\hline 1 & $1(3.8 \%)$ & $1(3.8 \%)$ & $\begin{array}{l}0 \\
(0.0 \%)\end{array}$ & 0.113 & $\begin{array}{l}0 \\
(0.0 \%)\end{array}$ & $\begin{array}{l}1 \\
(3.8 \%)\end{array}$ & 0.959 \\
\hline 2 & $8(30.8 \%)$ & $6(23.1 \%)$ & $\begin{array}{l}2 \\
(7.7 \%)\end{array}$ & & $\begin{array}{l}3 \\
(11.5 \%)\end{array}$ & $\begin{array}{l}5 \\
(11.5 \%)\end{array}$ & \\
\hline 3 & $9(34.6 \%)$ & $2(3.8 \%)$ & $\begin{array}{l}7 \\
(26.9 \%)\end{array}$ & & $\begin{array}{l}3 \\
(11.5 \%)\end{array}$ & $\begin{array}{l}6 \\
(23.1 \%)\end{array}$ & \\
\hline 4 & $3(11.5 \%)$ & $1(3.8 \%)$ & $\begin{array}{l}2 \\
(7.7 \%)\end{array}$ & & $\begin{array}{l}1 \\
(3.8 \%)\end{array}$ & $\begin{array}{l}2 \\
(7.7 \%)\end{array}$ & \\
\hline 5 & $5(19.2 \%)$ & $1(3.8 \%)$ & $\begin{array}{l}4 \\
(15.4 \%)\end{array}$ & & $\begin{array}{l}2 \\
(7.7 \%) \\
\end{array}$ & $\begin{array}{l}3 \\
(11.5 \%)\end{array}$ & \\
\hline
\end{tabular}

*P Value $<0.05$

\# Luminal A and B were not differentiated in all cases as $\mathrm{Ki}-67$ is not performed routinely in our centre.

BMI (Body Mass Index), NA (Non applicable), LVI (Lymphovascular invasion ), NI (Not identified), ER (Oestrogen receptor), PR (Progesterone receptor), HER2 (Epidermal growth factor receptor), TNBC (Triple negative breast cancer).

Lymph Node Mets Pre (Lymph node metastasis identified on pre-treatment biopsy or imaging). 
Lymph Node Metastasis Path (Lymph node metastasis identified on surgical specimen).

Figures

A
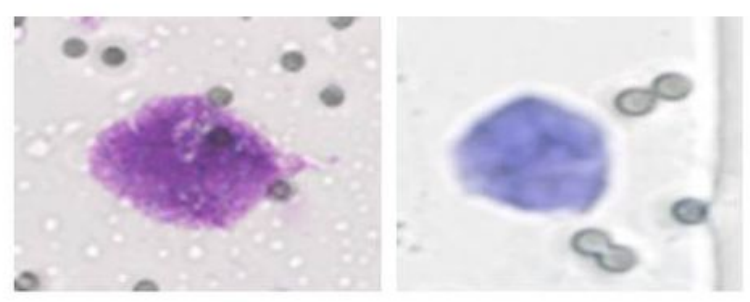

B

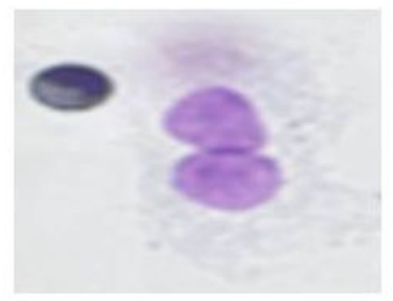

C
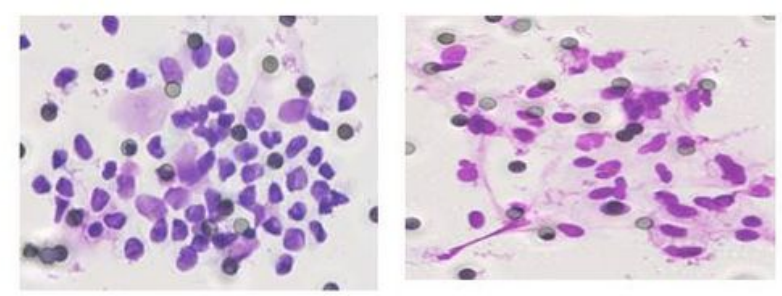

D

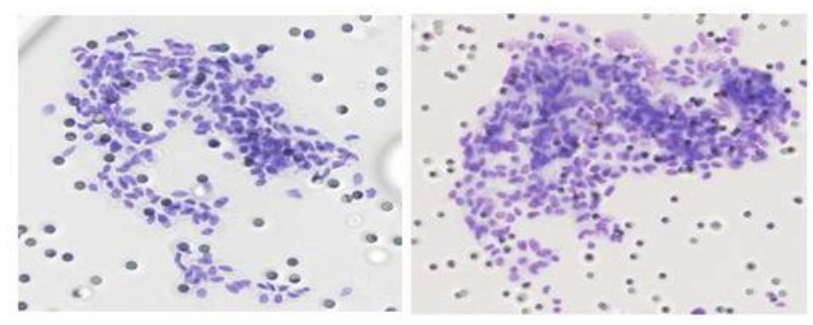

\section{Figure 1}

Multiple CTC physical forms were isolated from breast cancer patients. CTCs were enumerated by 2 pathologists and classified as (A) single cells, (B) doublets, (C+D) clusters / microemboli.

\section{Supplementary Files}

This is a list of supplementary files associated with this preprint. Click to download.

- FigureS1CTCCountChange.png

- BreastCancerSupplementaryTable1 revised.xlsx

- FigureS2CTCClusterchange.png 